Lepr Rev (1996) 67, 135-140

\title{
Active surveillance in leprosy: how useful is it?
}

\author{
R. P. CROFT \\ Danish Bangladesh Leprosy Mission, PO Box 3,PO\& Dt Nilphamari, \\ Bangladesh 5300
}

Accepted for publication 28 November 1995

\begin{abstract}
Summary In this paper, active surveillance is compared with self-reporting as a method of detecting new nerve function loss in leprosy patients who have completed multidrug therapy (MDT). Five hundred and three patients were selected according to new surveillance guidelines in one part of the DanishBangladesh Leprosy Mission leprosy control project working area. Surveillance coverage of $71 \%$ was achieved in a 7 -month period. During this time, 10 released-from-treatment (RFT) patients from among the study group were found to have acute nerve damage requiring prednisolone treatment. Out of the 10 , only 2 were detected actively; the remaining 8 self-reported.

It is concluded that health education given at RFT time is effective in motivating patients to self-report with acute nerve damage, and that the time spent on active surveillance could have been better used in other activities, i.e., case detection.

As a result of these findings, active surveillance has been abandoned in the leprosy control project.
\end{abstract}

\section{Introduction}

Post-MDT surveillance as a means of detecting relapse has for many years been part of the accepted wisdom of leprosy control. For example, the WHO Guide to Leprosy Control (1988) states that "clinical and bacteriological follow-up of cases after the completion of treatment is an important part of the current recommendation for MDT: it is essential for the assurance of success of treatment and for the early detection of any relapses'. ${ }^{1}$ Other important reference texts and reviews state the same, or very similar, view. ${ }^{2-4}$

Lately the validity of this rationale has been called into question. The most recent WHO technical report on the Chemotherapy of Leprosy recommends that since the risk of relapse after completion of WHO-MDT is negligible, it is no longer necessary to continue routine annual surveillance. Instead, patients should be taught to recognize the early signs of possible relapse or reactions and to report promptly for treatment. ${ }^{5}$

The early recognition and prompt, effective treatment of leprosy reactions and acute 
nerve damage is very important to prevent disability in leprosy with all its attendant problems. ${ }^{4}$ Regular sensory and motor testing has been recommended both during MDT and surveillance as a means of detecting early loss of function. ${ }^{4,6}$

A substantial number of leprosy reactions occur after completion of MDT, especially paucibacillary (PB) cases. Rose $\&$ Waters $^{7}$ concluded that the majority of Type 1 reactions in BT patients develop within the first 6 months of treatment, but that some may develop up to 3 years thereafter. Fine \& Lienhardt ${ }^{8}$ in their thorough review of reported studies concurred with this view.

On the face of it, it would seem logical to continue regular active surveillance of leprosy patients after completion of MDT in order to detect and treat acute nerve damage, and ideally that would be best for the patient. However, in busy leprosy control programmes with limited resources it may not be possible to conduct such follow-ups, as in many cases a home visit will be necessary and valuable time will be used chasing an ever-diminishing possibility of diagnosing a reactional episode. Further, annual surveillance has only a $50 \%$ chance of detecting nerve damage that has occurred within 6 months, the generally-agreed 'treatment window' for corticosteroid treatment. ${ }^{4,8} \mathrm{~A}$ better approach may be to motivate and educate the patient sufficiently to present to the leprosy clinic if he or she notices any new changes and indeed the WHO technical report on the chemotherapy of leprosy already referred to ${ }^{5}$ recommends this. As Rose \& Waters put it, 'A short time spent in patient education may save the patient from permanent disability'?

In the small study presented below, the numbers of patients with acute nerve damage requiring corticosteroid treatment found during active surveillance in a leprosy control programme, are compared with the numbers of patients self-presenting to a leprosy clinic with acute nerve damage.

\section{Patients and methods}

\section{DETAILS OF THE LEPROSY CONTROL PROGRAMME}

The study is based in the Danish-Bangladesh Leprosy Mission (DBLM), a large leprosy control project operating in four northern districts of Bangladesh, an area reckoned to have the highest prevalence of leprosy in the country $(5 / 1000) .{ }^{9}$ The project covers over $5000 \mathrm{~km}^{2}$ with a population of 4.3 million. Statistical information relating to leprosy control is given in Table 1.

Table 1. Statistical information relating to leprosy control in DBLM, 1994

$\begin{array}{lc}\text { New patients detected in } 1994 & 2871 \\ \text { Cases on treatment on } 31.12 .94 & 3070 \\ \text { Registered prevalence/10,000 } & 7 \cdot 13 \\ \text { Proportion of MB cases among new } & 22 \% \\ \text { Proportion with WHO disability grade } 2 \text { among new cases } & 8 \cdot 08 \% \\ \text { Proportion of children among new cases } & 19 \cdot 3 \% \\ \text { Case detection rate/10,000 } & 6 \cdot 68 \\ \text { PB/MDT completion rate } & 95 \cdot 7 \% \\ \text { MB/MDT completion rate } & 89 \cdot 4 \% \\ \text { MDT coverage } & 100 \% \\ \end{array}$


MDT is given as a fixed-dose regimen, as recommended by WHO. Patients are classified as paucibacillary (PB) or multibacillary (MB) on the basis of the total number of skin and nerve lesions and the skin-smear result: 10 or more skin and nerve lesions and/or a positive smear result is taken as indicating multibacillary disease.

New leprosy cases are detected in DBLM by a combination of active and passive case-finding methods. Rapid village surveys are carried out in areas thought by field staff to have a substantial number of cases, and contact surveys of all diagnosed cases are carried out for 2 years among the contacts of PB cases, and 5 years among MB contacts. Mass information campaigns to encourage self-reporting are carried out in the evenings using a slide programme, and in the day among smaller groups using flip charts and handbills.

The diagnosis of leprosy is usually made by experienced leprosy control supervisors at field clinics (of which there are 45) where skin smears are taken and MDT is given. All patients are followed up actively while on treatment, and all patients have sensory testing using a ball-point pen (as recommended by Jean Watson) ${ }^{10}$ and 'quick muscle testing' (QMT) using the modified MRC scale ${ }^{8}$ at each clinic visit. Any abnormality is immediately referred to the leprosy control supervisor and physiotechnician for confirmation. Patients presenting with reactional states and/or acute nerve damage are given treatment with prednisolone either in the field (according to a DBLM field treatment manual) or admitted to hospital if there are special reasons. Health education is strongly emphasized at each stage of the patient's treatment: diagnosis, case-holding and release from treatment (RFT) in order to improve compliance, increase the patient's understanding of his or her health problem and to motivate the patient to take responsibility for self-care. Of relevance here is the education given at release from treatment: the patient is instructed to come to clinic or visit the local fieldworker if he notices an increase in size or change in colour of his skin patches, or if he develops nerve pain, weakness, tingling or anaesthesia in his hands or feet. In other words, he is taught to refer himself if he develops signs of acute nerve damage/relapse.

\section{DETAils OF THE STUdy}

Leprosy control conducted by nongovernment organizations (NGOs) in Bangladesh is coordinated by the Leprosy Coordinating Committee (LCC) of Bangladesh. The LCC has a number of expert subcommittees, and in 1993 the Leprosy Control expert subcommittee looked at the subject of post-RFT surveillance and made some recommendations which were adopted by leprosy NGOs in the country. Their aims were twofold: 1, to maximize post-RFT surveillance in a group at high risk of developing reactions; and 2, to reduce the surveillance interval to 3 months so that any finding of acute nerve damage could have a good chance of successful corticosteroid treatment. Broadly, the high risk groups were defined as all PB cases up to 18 months after the end of treatment; MB cases during treatment only; and all cases (PB and MB) who had had a reactional episode during treatment. The following guidelines were made and adopted in 1994 by DBLM in part of its project area:

MB cases: If no reactions occurred during MDT, no active surveillance.

If a reaction occurred during treatment: nerve function assessment every 3 months until the patient has remained symptom-free for a whole year. 
PB cases: After release from treatment, all cases are followed with 3-monthly nerve function assessment for a further 18 months, i.e. 2 years from the start of MDT. If a leprosy reaction occurs during the 2-year period, then 3-monthly examinations are continued until the patient has remained symptom-free for a year.

DBLM's large leprosy control area is divided into 3 'fields', each with separate staff and administration. These surveillance guidelines were adopted in one of the three fields, Thakurgaon, where staffing is highest and where the author was living at that time. From July 1994 to January 1995 careful records were kept of cases found requiring corticosteroid treatment, and how they were detected. The results are presented below.

\section{DEFINITION OF A REACTIONAL EPISODE}

Without going into detail, the ' $D B L M$ field medical guidelines for the treatment of leprosy reactions' divides leprosy reactions into Type 1 (inflammation in skin patches \pm neuritis), Type 2, and pure neuritis without skin patch inflammation according to clinical findings. The severity of the reaction is also graded. Any case presenting with new nerve function loss (sensory and/or motor) of less than 6 months is started on 'f ull dose prednisolone treatment' (40 mg starting dose in adults tapering down over 16 weeks) after assessment by the physiotechnician. In this regard, the loss of 1 sensory point on hands or feet detected by ball-point pen testing, or the reduction by 1 point in the MRC muscle strength grade of any of the routinely tested movements was taken as evidence of nerve function loss. It is emphasized here that all patients with possible nerve function loss were examined by at least three staff: the leprosy control assistant, leprosy control supervisor and physiotechnician. All patients have sensory/motor testing at each clinic visit performed by at least one of the team; any abnormality must be confirmed by the other two before prednisolone may be started. Equivocal results were not accepted for prednisolone treatment and in such cases patients were re-assessed the following month. In this way, at the time of the study it was felt that the high sensitivity of such testing was acceptable.

In summary, for the purposes of surveillance unequivocal evidence of nerve function loss was taken as indicating the need for corticosteroid treatment.

\section{Results}

After explanation of the LCC surveillance rules to the field staff, clinic supervisors prepared a list of patients requiring follow-up. Table 2 shows the number of patients selected and their classification, and surveillance rates achieved.

Most patients required two surveillance visits during the 7-month period; some however were released from surveillance during the study period and therefore only had one visit; others were only made RFT during the study period and only qualified for one visit. For this reason the number of planned surveillance visits was less than expected if all patients had two visits.

Table 3 shows the number of patients with nerve function loss requiring full-dose 
Table 2. RFT patients selected for surveillance, classification and surveillance rates achieved July 1994January 1995, Thakurgaon field, DBLM

\begin{tabular}{|c|c|c|c|c|c|c|c|}
\hline \multirow{2}{*}{$\begin{array}{l}\text { Selected patients' MB/PB classification } \\
\text { Ridley-Jopling classification of selected patients }\end{array}$} & \multicolumn{2}{|c|}{$\begin{array}{c}\text { PB } \\
461 \\
91 \cdot 5 \%\end{array}$} & \multicolumn{3}{|c|}{$\begin{array}{l}\text { MB } \\
42 \\
8 \cdot 5 \%\end{array}$} & \multicolumn{2}{|c|}{$\begin{array}{l}\text { Total } \\
503 \\
100 \%\end{array}$} \\
\hline & $\begin{array}{l}\text { TT } \\
92 \\
18 \%\end{array}$ & $\begin{array}{l}\text { BT } \\
384 \\
77 \%\end{array}$ & $\begin{array}{l}\text { BB } \\
9 \\
2 \%\end{array}$ & $\begin{array}{l}\text { BL } \\
5 \\
1 \%\end{array}$ & $\begin{array}{l}\text { LL } \\
6 \\
1 \%\end{array}$ & $\begin{array}{l}\mathrm{PN} \\
7 \\
1 \%\end{array}$ & $\begin{array}{l}\text { TOT } \\
503 \\
100 \%\end{array}$ \\
\hline $\begin{array}{l}\text { Planned surveillance visits } \\
\text { Actual surveillance visits } \\
\text { Surveillance coverage }\end{array}$ & & & & $\begin{array}{l}918 \\
656 \\
71 \%\end{array}$ & & & \\
\hline
\end{tabular}

prednisolone found by active surveillance compared with those self-reporting for treatment.

Further, an additional 15 patients (14MB, 1PB) self-presented during the period who were not included in the study group but who had developed acute nerve damage. Of these 15 patients, 12 presented within 3 months of the onset of their reactional episode.

\section{Discussion}

This small study about the value of active surveillance has a number of interesting and important conclusions. First, and most importantly it can be seen that even though the surveillance guidelines were followed reasonably well (surveillance coverage $71 \%$ ), only a relatively small number of patients with nerve function loss were detected (2). Since most surveillance contacts were conducted at the patients' houses, a large amount of time and effort was expended to achieve this small result.

Second, it can be seen that out of all the patients with acute nerve damage detected (25), only 10 were included by the LCC surveillance guidelines. In other words, if the project had only relied on active surveillance and never received patients who self-referred, 15 patients would have fallen outside of the active surveillance group and would therefore not have received treatment. (Presumably the 8/10 who self-reported despite being in the active surveillance group would have been picked up at an active visit in time.)

Table 3. Patients with nerve function loss detected in the study period

\begin{tabular}{|c|c|c|c|c|c|c|c|}
\hline \multirow{2}{*}{$\begin{array}{l}\text { MB/PB classification } \\
\text { Ridley-Jopling classification }\end{array}$} & \multicolumn{2}{|c|}{$\begin{array}{c}\text { PB } \\
10\end{array}$} & \multicolumn{3}{|c|}{$\begin{array}{c}\text { MB } \\
0\end{array}$} & \multicolumn{2}{|c|}{$\begin{array}{c}\text { Total } \\
10\end{array}$} \\
\hline & $\begin{array}{c}\text { TT } \\
1\end{array}$ & $\begin{array}{c}\text { BT } \\
8\end{array}$ & $\begin{array}{c}\text { BB } \\
0\end{array}$ & $\begin{array}{c}\text { BL } \\
0\end{array}$ & $\begin{array}{c}\mathrm{LL} \\
0\end{array}$ & $\begin{array}{c}\text { PN } \\
1\end{array}$ & $\begin{array}{c}\text { Total } \\
10\end{array}$ \\
\hline $\begin{array}{l}\text { Patients with nerve function } 1 \\
\text { Patients self-reporting with ne }\end{array}$ & $\begin{array}{l}\text { tectec } \\
\text { nctio }\end{array}$ & vely & & & & & \\
\hline
\end{tabular}


Third, it can be argued that the surveillance guidelines followed were inadequate since in this study the majority of RFT patients detected with acute nerve damage were not included in the defined group (15/25). Of particular interest is the fact that all 10 of the patient who developed acute nerve damage during the study period (whether detected actively or passively) were paucibacillary; but 14/15 of the patients not included in the cohort were multibacillary. The guidelines were not at all effective at 'catching' MB cases developing a reaction after RFT.

However, despite the probable inadequacies of the surveillance guidelines, it seems clear that 'passive surveillance', i.e. self-reporting, is effective as a means of finding patients with acute nerve damage since $8 / 10$ patients included in the study presented in this way; indeed, they presented sooner than they would have done had they been detected actively. Out of the group of 15 patients presenting with acute nerve damage not included in the study group, 12 presented within 3 months of the start of the reactional episode, adding further weight to the conclusion that patients present themselves reasonably soon. A patient's ability to recognize early signs of nerve damage is dependent on health education received during his treatment period, especially at his last clinic visit. Effective health education can therefore be viewed as a time-saving and very effective alternative to active surveillance.

In our project area, field staff estimated that one surveillance visit required at least one hour of time. If 600 visits were necessary (a few patients came to clinic), then 600 worker-hours were used. During 1994, field staff were also involved in active case-finding using a rapid survey method. It is reckoned that one field worker can examine 100 people a day; and on average 3 new leprosy cases per 1000 population examined are detected. Thus if the amount of time used on active surveillance had been applied to a rapid survey, then 26 new leprosy cases would have been detected-a considerably more valuable exercise in terms of primary prevention of disability.

As a result of these findings, active surveillance has been abandoned as a routine field activity in DBLM.

\section{Acknowledgment}

The author is grateful to Dr W. C. S. Smith, Reader in Public Health at the University of Aberdeen, Scotland for his helpful comments and encouragement in this study.

\section{References}

${ }^{1}$ WHO. 'A Guide to Leprosy control' 2nd ed., Geneva, 1988, p. 88.

2 Hastings, RC. Leprosy, Churchill Livingstone, UK, 1988.

3 WHO. WHO Expert Committee on Leprosy, 6th report, WHO, Geneva, 1988.

${ }^{4}$ Becx-Bleumink M et al. The management of nerve damage in the leprosy control services. Lepr Rev, 1990; 61: 1-11.

5 WHO. Chemotherapy of Leprosy, WHO Technical report series 847, Geneva, 1994.

6 Watson, JM. Disability control in a leprosy control programme. Lepr Rev, 1989; 60: 169-177.

7 Rose P, Waters MFR. Reversal reactions in leprosy and their management. Lepr Rev, 1991; 62: 113-119.

${ }^{8}$ Fine PEM, Lienhardt C. Type 1 reactions, neuritis and disability in leprosy. What is the current epidemiological situation? Lepr Rev, 1994; 65: 9-33.

9 Richardus JH, Croft RP. Estimating the size of the leprosy problem: the Bangladesh experience. Lepr Rev, 1995; 66: 158-164.

10 Watson, JM. Essential action to minimise disability in leprosy patients. The Leprosy Mission International, Stanley L Hunt Ltd, 1988. 